\title{
DEVELOPMENT OF X-43A MACH 10 LEADING EDGES
}

\author{
C. W. Ohlhorst ${ }^{\#}$, D. E. Glass ${ }^{+}$, W.E. Bruce ${ }^{+}$, M.C. Lindell^, W. L. Vaughn ${ }^{\#}$, and R.W. Smith ${ }^{+}$ \\ NASA Langley Research Center, Hampton, VA \\ R. B. Dirling Jr., Manager \\ SAIC, Fountain Valley, CA \\ P. A. Hogenson, TPS Consultant \\ Boeing Company, Huntington Beach, CA \\ J. M. Nichols, Contracts and Procurement Manager, N.W. Risner, Vehicle Manufacturing Lead Engineer, \\ D. R. Thompson, Quality Assurance Manager \\ ATK-GASL,Tullahoma, TN \\ W. Kowbel, Senior Vice President \\ MER Corp., Tucson, AZ \\ B. J. Sullivan, Director \\ Materials Research \& Design, Inc., Wayne, PA \\ J. R. Koenig, Head, Materials Research Department, and J. C. Cuneo, Manager, Materials Engineering \\ Group, Southern Research Institute, Birmingham, AL
}

\begin{abstract}
$\underline{\text { Abstract }}$
The nose leading edge of the Hyper-X Mach 10 vehicle was orginally anticipated to reach temperatures near $4000^{\circ} \mathrm{F}$ at the leading-edge stagnation line. A SiC coated carbon/carbon $(\mathrm{C} / \mathrm{C})$ leading-edge material will not survive that extreme temperature for even a short duration single flight. To identify a suitable leading edge for the Mach 10 vehicle, arc-jet testing was performed on thirteen leading-edge segments fabricated from different material systems to evaluate their performance in a simulated flight environment. Hf, $\mathrm{Zr}, \mathrm{Si}$, and $\mathrm{Ir}$ based materials, in most cases as a coating on $\mathrm{C} / \mathrm{C}$, were included in the evaluation. Afterwards, MER, Tucson, AZ was selected as the supplier of the flight vehicle leading edges. The nose and the vertical and horizontal tail leading edges were fabricated out of a 3:1 biased high thermal conductivity $\mathrm{C} / \mathrm{C}$. The leading edges were coated with a three layer coating comprised of a $\mathrm{SiC}$ conversion of the top surface of the $\mathrm{C} / \mathrm{C}$, followed by a chemical vapor deposited layer of $\mathrm{SiC}$, followed by a thin chemical vapor deposited layer of HfC. This paper will describe the fabrication of the Mach $10 \mathrm{C} / \mathrm{C}$ leading edges and the testing performed to validate performance.
\end{abstract}

\# Materials Engineer, + Aerospace Technologist, ^ Aerospace engineer

The use of trademarks or names of manufacturers in this paper is for accurate reporting and does not constitute an official endorsement, either expressed or implied, of such products or manufacturers by the National Aeronautics and Space Administration.

\section{Cleared for Public Release}


two horizontal tailpieces, two upper vertical tailpieces and two lower vertical tail pieces, as shown in Fig. 1. For the Mach 7 flight vehicles, only seven of the leading-edge pieces were fabricated out of $\mathrm{C} / \mathrm{C}$ since thermal analysis indicated that the four vertical tailpieces would not be subjected to high enough temperatures to require $\mathrm{C} / \mathrm{C}$, and thus could be fabricated from a Haynes alloy. For each of the two Mach 7 flights, the seven leading edge $\mathrm{C} / \mathrm{C}$ flight hardware pieces were fabricated by Goodrich Corporation, Santa Fe Springs, California, USA.

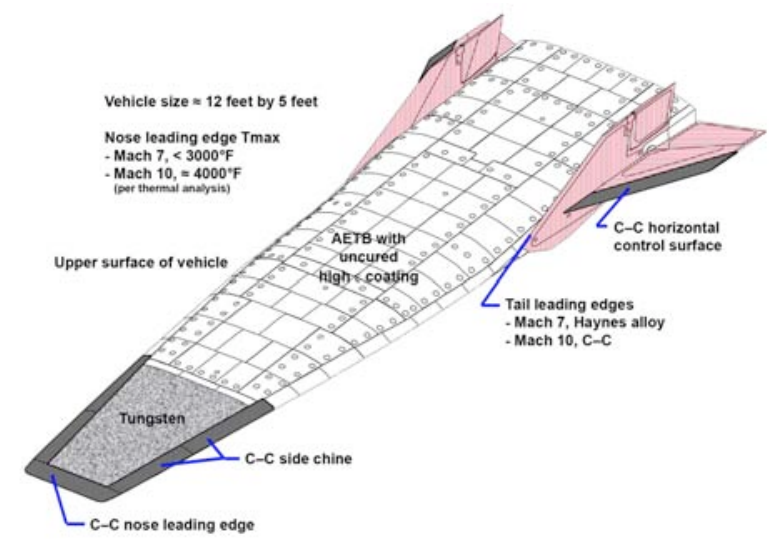

Figure 1. Thermal protection for the X-43A Mach 7 vehicle.

Various views of the X-43A flight vehicle are shown in Fig. 2. The front and side views show the sharp leading edges. The desired nose tip radius on the Hyper-X flight vehicles was 0.030 in. Aero thermal heating on sharp leading edges such as this produce high temperatures and high thermal gradients.

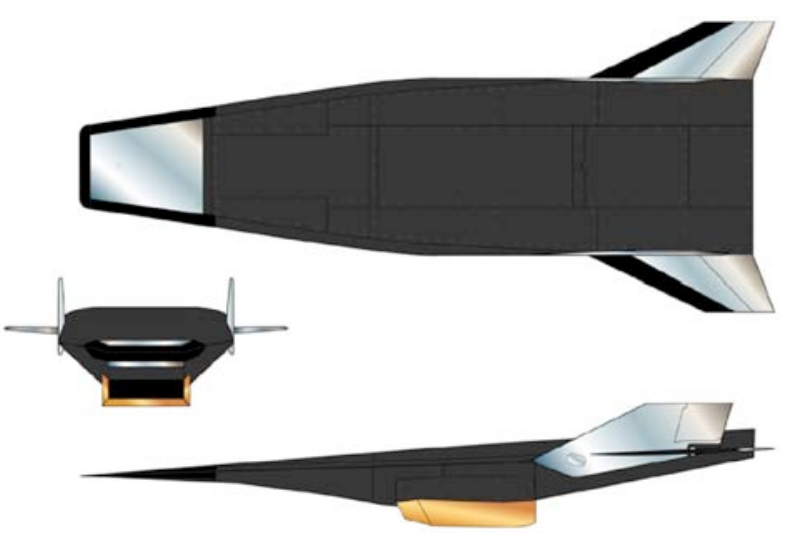

Figure 2. Three views of X-43A flight vehicle.
In order to reduce the nose tip temperature and reduce thermal gradients, it was decided to construct the nose leading edge using high thermal conductivity carbon fibers woven in an unbalanced weave to give more fibers perpendicular to the leading edge. A K321 fiber woven in a 4:1 unbalanced weave was baselined for the nose leading edge of the Mach 7 vehicle. Thermal analysis of this baselined construction indicated that the nose maximum temperature would only get to $3000^{\circ} \mathrm{F}$, so a silicon carbide ( $\mathrm{SiC}$ ) oxidation coating system was deemed viable. Even though a 4:1 unbalanced weave was baselined, the Mach 7 nose pieces were fabricated from a 2-D billet of K321, 5:1 fabric. The difference in substrate weave architecture resulted from the 5:1 fabric being more readily available than the $4: 1$ fabric, and that it would conduct more heat away from the nose tip. The two horizontal tail control surface pieces for each Mach 7 vehicle were fabricated from quasiisotropic $\mathrm{K} 321$, and coated with $\mathrm{SiC}$ while the four side chines were fabricated from 3-D needled C/C PAN-based fiber and coated with SiC. Figure 3 shows the assembled Mach 7 nose and forward chine flight hardware.

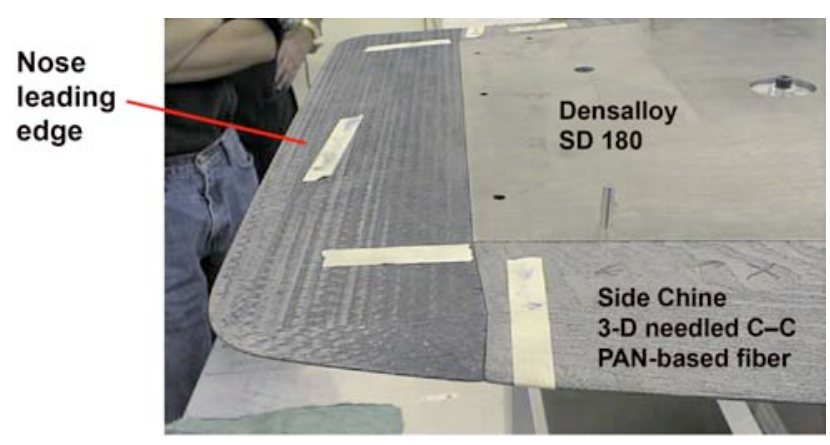

Figure 3. Goodrich X-43A Mach 7 C/C nose leading-edge flight hardware assembly.

\section{Development of Mach 10 Leading Edges}

\section{Coating Evaluation}

Thermal analysis for the Mach 10 vehicle, with a 0.030 in. nose radius, predicted temperatures that would approach $4000^{\circ} \mathrm{F}$ at the nose tip. The $4000^{\circ} \mathrm{F}$ temperature greatly exceeds the use temperatures of SiC-based coating systems even for a short duration, single flight. To identify a suitable leading edge for the Mach 10 vehicle, arc-jet testing was performed on leading-edge segments fab- 
ricated using thirteen different material systems in the $\mathrm{H} 2$ arc-jet facility at the Arnold Engineering Development Center (AEDC), Arnold Air Force Base, TN in early 2000. The objective was to evaluate potential coatings for single use on a $\mathrm{C} / \mathrm{C}$ substrate at Mach 10 heating conditions for 130 seconds. The flight conditions simulated were those of the Mach 10 flight.

The K321 fiber, 5:1 C/C substrate used in the Mach 7 fabrication was used by many of the vendors. Some vendors selected other substrates. Most of the coating systems provided for evaluation were $\mathrm{Hf}, \mathrm{Zr}, \mathrm{Si}$, and $\mathrm{Ir}$ based materials. The range of materials and processes evaluated are shown below:

Substrates

C/C (5:1, K321 fiber, P-30X)

Functionally graded material (5:1, K321 fiber)

W-1\% La, TZM, ZrB $2 / 20 \% \mathrm{SiC}$

Coating components

$\mathrm{HfC}, \mathrm{HfO}_{2}, \mathrm{HfB}_{2}, \mathrm{ZrC}, \mathrm{ZrB}_{2}, \mathrm{SiC}, \mathrm{Si}_{3} \mathrm{~N}_{4}$, $\mathrm{MoSi}_{2}$

Ir, Re, $\mathrm{ZrC} / \mathrm{W}-\mathrm{Re}$

Coating processes

Chemical Vapor Infiltration (CVI), Chemical Vapor Deposition (CVD), Chemical Vapor Reaction (CVR), Reaction sintered, Molten salt bath, Plasma spray, Paint on, Hot pressing

Figure 4 shows the dimensions of the test specimens; 1.9 in. wide, 4 in. long with a tip radius of $0.030 \mathrm{in}$.

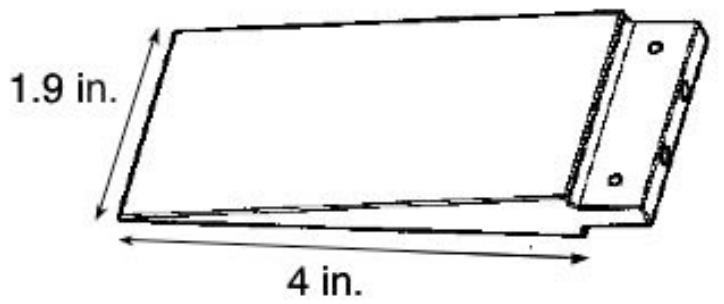

Figure 4. Specimen test size for material evaluations in the 2000 AEDC arc-jet test program.
As a result of the testing, MER Corporation was selected as the supplier of the $\mathrm{C} / \mathrm{C}$ leading edges. MER fabricated the leading-edge parts under contract to ATK-GASL of Tullahoma, TN (formerly Allied Aerospace). A Mach 10 leading edge advisory committee (M10LEC) was selected to provide technical oversight to MER during the fabrication of the eleven $\mathrm{C} / \mathrm{C}$ leading-edge parts. MER utilized a high thermal conductivity P-30X fiber as they did for the AEDC arc-jet tests. The coating selected was a three-layer coating comprised of a $\mathrm{SiC}$ conversion of the top surface of the $\mathrm{C} / \mathrm{C}$ substrate, followed by a $\mathrm{CVD}$ layer of $\mathrm{SiC}$, followed by a thin CVD layer of HfC.

Weave, Layup, and Heat-Treatment Temperature $\underline{\text { Selection }}$

A numerical model of the Hyper-X nose components was developed at NASA Langley to calculate the aerothermal heating, thermal response, and structural response. A typical finite element model of the nose is shown in Fig. 5.

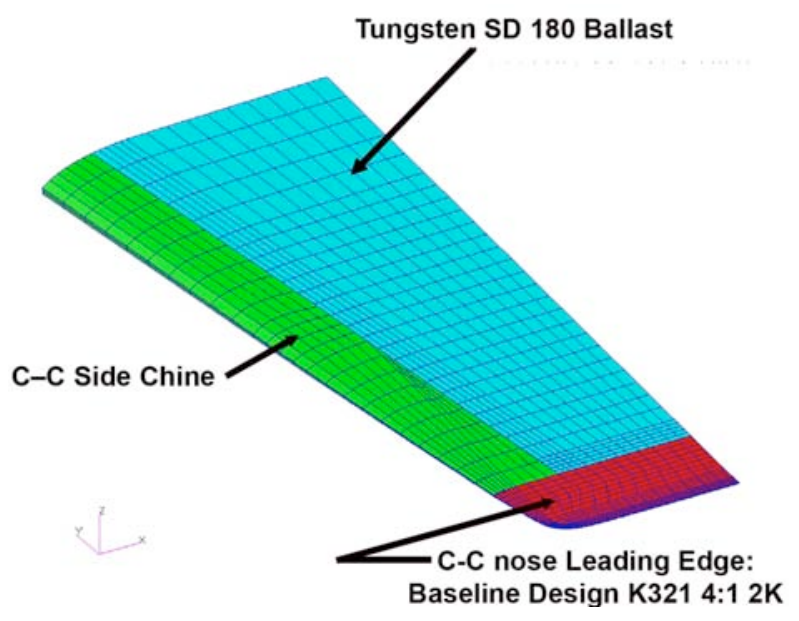

Figure 5. Finite element model of Hyper-X nose component.

The process of assessing the temperatures and stresses in the nose leading edge first required an iterative solution between the aerothermal heating and the transient heat transfer. Times at which maximum temperatures and temperature gradients occur were determined, and temperature distributions at these times were provided for an assessment of thermal stresses. Details of the analysis process can be found in reference [1]. 
As illustrated in Fig. 6, the high thermal gradient at the tip of the nose leading edge leads to high thermal stresses in the spanwise direction, parallel to the tip of the leading edge. The stress of primary concern is the weak axis direction compressive stress along the leading edge. Available existing data on high thermal conductivity pitch fiber $\mathrm{C} / \mathrm{C}$ composites implied that the weak axis compressive stress along the leading edge could cause failure for an unbalanced 4:1 C/C.

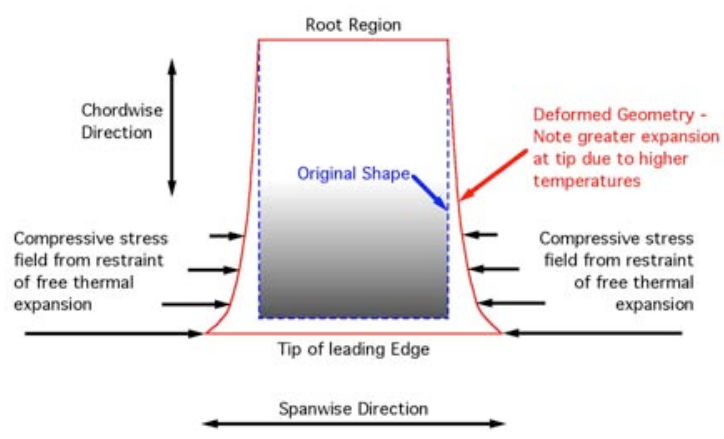

Figure 6. Schematic diagram of planform view indicating compressive stress field parallel to leading edge.

The use of heat-treated pitch fiber P-30X, unbalanced $4: 1$ weave was motivated by the desire to achieve the highest possible chordwise direction thermal conductivity by having the greatest possible fiber volume percentage oriented in the chordwise direction. Due to the concerns regarding potential spanwise direction compressive stress failure at the tip of the leading edge, Materials Research \& Design, Inc. (MR\&D), Wayne, PA, USA, estimated the thermal conductivity, thermal expansion, and thermo-mechanical properties of the $\mathrm{C} / \mathrm{C}$. Classical micromechanical analysis methods were used for these calculations.

MR\&D reviewed the available data on high thermal conductivity $\mathrm{C} / \mathrm{C}$ composite data from the NASA Solar Probe [2] and the U.S. Navy Advanced Thermal Applications for $\mathrm{C} / \mathrm{C}$ (ATACC) efforts. From knowledge of the fiber architectures, the matrix composition, the fiber volume fraction, and the heat treatment temperature, fiber and matrix constituent properties, including effective strengths, were back-calculated from these data. The constituent properties were then used in for- ward micromechanical calculations to estimate the temperature-dependent moduli, thermal expansions, and thermal conductivities of the proposed P-30X, unbalanced 4:1 weave.

NASA Langley performed additional transient heat transfer and thermal stress analyses of the hypersonic vehicle with the preflight predicted trajectory, using new $\mathrm{C} / \mathrm{C}$ properties provided by MR\&D. These analyses again predicted peak temperatures of approximately $3800^{\circ} \mathrm{F}$ at the tip of the leading edge, with the peak thermal gradients again occurring $79 \mathrm{sec}$. into the flight trajectory. The calculated spanwise compressive stresses exceeded the MR\&D-estimated spanwise compressive strength at the maximum temperature condition. Accordingly, MR\&D recommended that a 3:1 reinforcement be used for the Mach 10 nose instead of the 4:1 reinforcement. This change would allow more fibers to be oriented in the spanwise direction, thus increasing the fiberdominated compressive strength. This recommendation was accepted by the M10LEC.

Table 1. Leading-Edge Design and Requirements

\begin{tabular}{|c|c|c|c|}
\hline Part & $\begin{array}{c}\text { Nominal } \\
\text { Size, in. }\end{array}$ & $\begin{array}{c}\text { Max. } \\
\text { Temp., }\end{array}$ ' $F$ & $\begin{array}{c}\text { Major } \\
\text { Concerns }\end{array}$ \\
\hline Nose & $\begin{array}{c}18 \times 5 \times \\
0.6\end{array}$ & 3800 & $\begin{array}{c}\text { High } \\
\text { thermal } \\
\text { gradient }\end{array}$ \\
\hline Chine & $18 \times 4 \times 3$ & 1300 & Thick \\
\hline $\begin{array}{c}\text { Horizontal } \\
\text { Tail }\end{array}$ & $\begin{array}{c}33 \times 5 \times \\
0.6\end{array}$ & 3200 & $\begin{array}{c}\text { High } \\
\text { temperature } \\
\text { at root, } \\
\text { clearance }\end{array}$ \\
\hline $\begin{array}{c}\text { Vertical } \\
\text { Tail }\end{array}$ & $\begin{array}{c}14 \times 5 \times \\
0.7, \\
8 \times 5 \times 0.6\end{array}$ & 2800 & $\begin{array}{c}\text { Fixed, } \\
\text { clearance }\end{array}$ \\
\hline
\end{tabular}

Table 1 shows the leading-edge design requirements and indicates the major concern of each part type. Major concerns for the nose were tip temperature and high thermal gradients leading to high compressive stresses. The chine maximum temperature was only $1300^{\circ} \mathrm{F}$, however, there was a major concern about the fabrication of such a thick part. The horizontal tailpieces were very 
long, 33 in. leading to concerns of coating uniformity. High temperature at the root clearance was another possible concern for these pieces. The upper vertical tail pieces were 14 in. long, 5 in. wide and $0.7 \mathrm{in}$. thick while the lower vertical was 8 in. long, 5 in. wide and 0.6 in. thick. A fixed clearance was the major concern with these parts.

Table 2 shows the fiber, weave, and lay-up of all the parts. All parts were fabricated using P-30X fiber. All parts, except for the 4 chine parts, were fabricated from the recommended unbalanced 3:1 weave using a 2D warp aligned lay-up. The performs were woven by Textile Technologies, Inc.

Table 3. Mach 10 Leading-Edge Material Preform Design

\begin{tabular}{|c|c|c|c|}
\hline Part & Fiber & Weave & Lay-up \\
\hline Nose & P-30X & $\begin{array}{c}\text { Unbalanc } \\
\text { ed 3:1 }\end{array}$ & $\begin{array}{c}\text { 2D Warp } \\
\text { Aligned }\end{array}$ \\
\hline Chine & P-30X & $\begin{array}{c}\text { Balanced } \\
1: 1\end{array}$ & $\begin{array}{c}\text { 2D Quasi- } \\
\text { isotropic }\end{array}$ \\
\hline $\begin{array}{c}\text { Horizont } \\
\text { al Tail }\end{array}$ & P-30X & $\begin{array}{c}\text { Unbalanc } \\
\text { ed 3:1 }\end{array}$ & $\begin{array}{c}\text { 2D Warp } \\
\text { Aligned }\end{array}$ \\
\hline $\begin{array}{c}\text { Vertical } \\
\text { Tail }\end{array}$ & P-30X & $\begin{array}{c}\text { Unbalanc } \\
\text { ed 3:1 }\end{array}$ & $\begin{array}{c}\text { 2D Warp } \\
\text { Aligned }\end{array}$ \\
\hline
\end{tabular}

The chine material was a conventional 2D C/C for two primary reasons. First, the heating rate was low enough that high thermal conductivity was not required to reduce the temperature. Second, since the thickness was large, a conventional 2D composite had the best chance of surviving processing without delamination. Hence, the use of a conventional, balanced 1:1 fabric and a quasi-isotropic lay-up was utilized. Bending loads were also relatively low at the tang so quasi-isotropic strength was sufficient and a warp-aligned composite was not required.

\section{Slotting Evaluation}

The $\mathrm{C} / \mathrm{C}$ utilized for the nose leading edge of the Hyper-X Mach 10 vehicle was anticipated to have large compressive thermal stresses in the spanwise direction. The large thermal stresses were due to the extremely large chordwise thermal gradients at the nose. Numerical analysis indicated that there might be a problem with material failure due to stresses and/or strains above the strength of the material. These concerns over the possibility of leading-edge failure at the nose tip led to a consideration of possibly slotting the nose leading edge to relieve the stresses. Several additional experts were combined with the core M10LEC to form a "Slotting Evaluation" team. This slotting team recommended and performed several tests to answer the question of whether or not slotting was required and a viable solution.

Questions and concerns that the team dealt with were: Would the substrate fail due to the large thermal stresses? Would the coating buckle and possibly spall? If slotting was required, how far apart would the slots need to be and how could it be ensured that the slot surfaces were coated? Several tests were performed to address the concerns.

The first test involved the laser heating of uncoated leading-edge specimens in the Laser Hardened Materials Evaluation Lab (LHMEL) at AFRL, WPAFB, OH. The tests were conducted by Southern Research Institute (SRI). The primary objective was to thermally load the specimens by simulating the maximum aerothermal heating environment to see if significant material damage or buckling would occur.

Because of limitations of the LHMEL laser spot size, a segment of the leading edge considerably smaller than the full scale flight hardware span length was used as the test model. Since the leading-edge compressive stresses are a function of the leading-edge spanwise length, it was recognized that the thermal gradient in the test model would need to exceed the flight thermal gradient to induce thermal stresses comparable to expected flight stresses in the test model. It was also desirable to not exceed the maximum predicted flight temperature at the test model stagnation point. Therefore, the plan was to immediately apply the maximum heat flux to the test model and quickly elevate the part to the maximum temperature and induce a larger thermal gradient than would be expected in flight; thereby, inducing thermal stresses equivalent to flight conditions. During testing a thermal gradient duplicating the expected 
flight gradient was induced in the test model; however, the thermal gradient could not be increased. Therefore, the thermal stresses in the test part did not approach the expected flight stresses. Because of this limitation, though no failure was observed, the tests were considered inconclusive.

It was then decided to test the $\mathrm{C} / \mathrm{C}$ material utilizing a 4-point bend test. The flexure specimen configuration is illustrated in Fig. 7. This test was developed by MR\&D and SRI, and was designed to induce a compressive stress state in the spanwise direction equal to the spanwise direction compressive stress at the tip calculated from the temperature gradient of the flight condition. SRI conducted the elevated temperature 4-pt bending tests on uncoated material at $3000^{\circ} \mathrm{F}$ and $3800^{\circ} \mathrm{F}$.
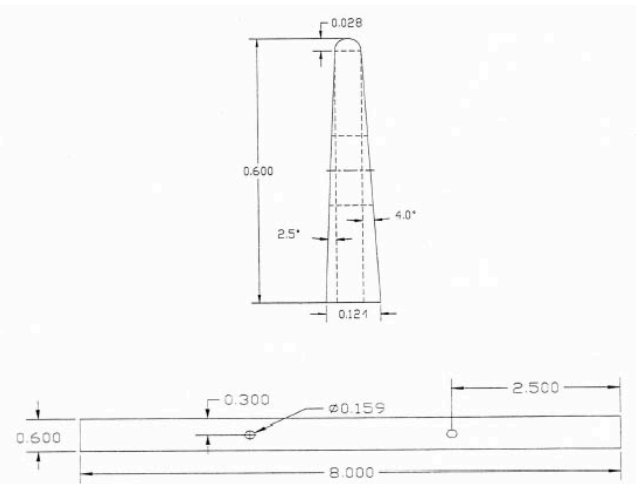

Figure 7. Four-point bend flexure specimen design details for compressive strength testing.

In both the $3000^{\circ} \mathrm{F}$ and $3800^{\circ} \mathrm{F}$ tests, the maximum compressive strain was above the predicted strain during flight. (Strain was used to evaluate the material instead of stress since it was felt to be s a better gage of material capability for the leading edge conditions.) There was no indication of compressive failure in the tip region. The test specimen failed at the loading holes, preventing increasing the load until tip failure.

Both the LHMEL and 4-pt bend tests were on uncoated material. There were concerns about the fact that coated specimens were not tested, as well as possible coating spallation and reduced compressive strengths from the coating process. It was believed that cracking of the coatings could not be prevented by slotting unless the slots were unrealistically close, and thus slotting would not prevent coating spallation. Thus, the strength issue appeared relevant to the uncoated material only. Based on the 4-point bend test results, coupled with the LHMEL test results and the prior AEDC tests, it was determined that slots were not necessary to prevent failure of the uncoated $\mathrm{C} / \mathrm{C}$ material and the Hyper-X M10LEC recommended not slotting the M 10 nose leading edge.

A few months after the decision was made not to slot the leading edge, MER delivered coated flexure coupons to SRI, who then duplicated the uncoated coupon flexure tests. The SRI-measured results indicated that the compressive properties of the $\mathrm{HfC} /$ conversion coated MER $\mathrm{C} / \mathrm{C}$ material actually exceeded those of the uncoated $\mathrm{C} / \mathrm{C}$ material. The coated $\mathrm{C} / \mathrm{C}$ composite compressive strengths resulting from the SRI 4-point bend testing provided a positive stress margin of safety and gave confidence that the leading edges would not fail due to the high thermal gradient at the tip of the leading edge.

\section{Tip Erosion}

The initial AEDC arc-jet test in 2000 was conducted on a specimen only $1.9 \mathrm{in}$. wide. The final design of the nose leading edge had several differences from the original specimen tested in 2000 including a different material lay-up, a different heat treat temperature, and a different coating process. The coating process was changed because the full scale hardware could not fit into the original apparatus used to coat the original, smaller test specimens. Because of these differences, it was felt prudent to repeat the 2000 test with the new hardware configuration. It would be ideal to test the full-scale nose so that thermal stresses would match flight conditions; however, the largest model span length that could be accommodated in the AEDC, $\mathrm{H} 2$ facility at the required test conditions was approximately 6 in. Therefore, the two test specimens were fabricated with a span length of 5.89 in., and the test were performed at identical conditions as the initial test. A post test picture of one of the test models is shown in Fig. 8. As can be seen in the figure, the nose tip eroded. Buckling or shear failure was not observed due to the span length limitation, but erosion along the full length of the leading edge was observed on both models. 


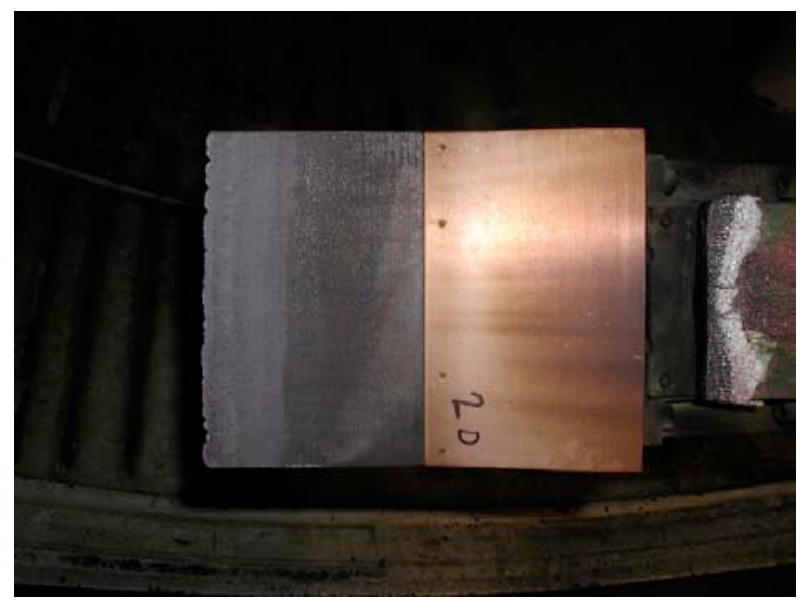

Figure 8. Arc-jet model tested at AEDC in February 2004.

After the unexpected erosion in the AEDC arcjet test, various options were considered and a modified approach was selected for supplying the nose leading edge flight hardware. It was decided to machine a new nose leading edge out of an existing $\mathrm{C} / \mathrm{C}$ billet. This nose leading edge would be redesigned to have a 0.050 -in. radius, and the new nose leading edge would be heat treated at a temperature to be specified by the M10LEC.

As mentioned previously, two differences in the leading edge arc-jet specimens besides size were weave architecture (4:1 vs $3: 1)$ and heattreatment temperature. MER had previously fabricated extra non heat-treated billets of unbalanced 3:1 fabric. MER had no unbalanced 4:1 fabric and there was not enough time to obtain any, so there was no option to compare weaves. One possible reason for the erosion (not proven) was that the tip got hotter since there were less fibers perpendicular to the leading edge and those fibers had a lower thermal conductivity due to the lower heat-treat temperature. A second possible reason (not proven) was that the fibers, being less graphitic due to the lower heat-treat temperature, were converted more fully to $\mathrm{SiC}$ during the initial coating process, and thus the tip itself might have been almost completely $\mathrm{SiC}$, thus reducing even further the conduction of heat away from the tip. Because of the discrepancy between the two AEDC tests, an action was initiated to decide what would be the best heat-treatment temperature to use for the nose flight hardware. This decision would only apply to the nose flight hardware.
The M10LEC overseeing the fabrication of the nose decided to investigate the use of the heattreatment temperatures used previously, and there were no obvious reasons to look at other temperatures. The parameters of interest were thermal conductivity at maximum use temperature in the direction perpendicular to the nose, compression strength and modulus parallel to the nose span wise direction, and the amount of fiber conversion during the initial chemical vapor reaction coating step.

MER had some spare material heat treated at both heat-treatment temperatures for thermal conductivity and compression tests. A study of available measured and predicted thermal conductivity data indicated that the differences in thermal conductivity of composites made with similar fibers and similar heat-treatment temperatures would be minor. Thermal analyses indicated that the difference would not be significant in terms of tip temperature. It was believed that the thermal conductivity difference between the two heat-treatment temperatures would not be significant at the maximum temperature, but it was likely that the material heat-treated at the higher temperature would have a slightly higher value.

Compression tests were conducted on specimens heat-treated at both temperatures. The compression strengths (the higher the better) were slightly lower for the material heat-treated at the higher temperature. The modulus values were basically the same. The compression strength differences were not significant.

Fibers heat-treated at the higher temperature were more graphitic than fibers heat-treated at the lower temperature. Being more graphitic, the fiber conversion rate to $\mathrm{SiC}$ would be less for the material heat-treated at the higher temperature, leaving more fibers available at the tip to conduct heat away. There would more fibers available at the tip to conduct heat away if the material was heattreated at the higher temperature, and the higher heat-treatment temperature was selected.

\section{Delaminated Chine}

During the fabrication cycle of the parts, periodic fit checks were required to ensure the parts fit 
on the vehicle. Fabricating the parts to the exact required tolerances was not a trivial task. Thermal expansion of the parts, substrate contraction and expansion during the fabrication and coating process, plus coating thickness all had to be considered. During installation, gaps had to be maintained to allow for thermal expansion so as not to create undue stresses. Accurate thermal expansion data in all directions was required to calculate the expected maximum thermal expansion that would occur in each part and in each direction, such that the gap sizes needed to account for part expansion, could be calculated.

During one of the fit checks, a delamination was found in a forward side chine. The problem was solved by MER fabricating a replacement part. However, the concern generated by discovering this flawed part late in the process raised questions as to whether other parts might also be flawed. It was requested that the M10LEC look into the possibility of using Non Destructive Evaluation (NDE) techniques to verify part integrity, and recommend to the Hyper-X program management what further action, if any, to take.

The M10LEC and selected other experts evaluated the feasibility of using NDE techniques for evaluating the fabrication quality of the Hyper-X $\mathrm{C} / \mathrm{C}$ components. It was determined that $\mathrm{NDE}$ techniques were available that could image composite components like the ones on the Hyper-X vehicle and provide information on the internal structure. However, this data was not always straightforward and easy to interpret.

The damaged (delaminated) forward side leading edge chine and one of the nose samples tested in the arc heater were sent to NASA Langley for evaluation. The NDE personnel at Langley had considerable experience evaluating shuttle RCC; however, there was uncertainty if they could image a thick component such as the side chine. They were able to image the chine, and the NDE test showed density variations in the side chine and no density variations in the nose. Because it was not possible to quantify the severity of the density variations from the NDE images, the M10LEC decided to perform a load proof test on the side chine. Reference 3 gives full details of the load proof test. The chine was supported as it would be on the vehicle and was uniformly loaded to over two times the expected flight load. The chine passed the test and no damage was observed, indicating that the density variations that were observed in the NDE tests were not detrimental to part integrity.

All of the Hyper-X C/C components had previously passed X-ray tests and coin tap tests. Because of the potential complexity of correlating and interpreting the NDE results, the M10LEC and selected other experts recommended that additional NDE techniques to verify the quality of the $\mathrm{C} / \mathrm{C}$ components not be pursued further. The M10LEC believed that the X-ray and coin tap tests were sufficient to verify the quality of the parts. Therefore, even though NDE techniques were available that may have provided additional data on the internal structure of the $\mathrm{C} / \mathrm{C}$ components, it was believed that performing NDE on these components would not add value. It was thus recommended to the Hyper-X program office, that the $\mathrm{C} / \mathrm{C}$ parts be accepted for flight based on the test performed.

\section{Concluding Remarks}

MER Corporation was selected to fabricate the coated $\mathrm{C} / \mathrm{C}$ leading edges for the Hyper-X Mach 10 vehicle. The substrate chosen was the Amoco's $\mathrm{P}-30 \mathrm{X}$ fiber, woven in a 3:1 unbalanced weave, woven by Textile Technologies, Inc. Seven of the eleven leading edge parts were coated with a three layer coating comprised of a $\mathrm{SiC}$ conversion of the top surface of the $\mathrm{C} / \mathrm{C}$, followed by a CVD layer of $\mathrm{SiC}$, followed by a thin CVD layer of HfC. The four chine parts were coated with only the first two layers. Fabrication of the eleven $\mathrm{C} / \mathrm{C}$ parts was a challenge and many obstacles had to be overcome. This paper described the fabrication of the Mach $10 \mathrm{C} / \mathrm{C}$ leading edges and the testing performed to validate performance. The Hyper-X Mach 10 vehicle successfully flew on November 16, 2004 and all the leading edge parts performed as expected. The successful flight demonstrates that, for at least a single short mission, $\mathrm{C} / \mathrm{C}$ composites are a viable material for hypersonic vehicle sharp leading edges. 
C. W. Ohlhorst, et. al., Development of X-43A Mach 10 Leading Edges, IAC-05-D2.5.06

\section{$\underline{\text { References }}$}

1. C.P. Leonard, R.M. Amundsen, and W.E. Bruce: Hyper-X Hot Structures Design and Comparison with Flight Data. AIAA-2005$3438,13^{\text {th }}$ AIAA/CIRA International Space Planes and Hypersonics Systems and Technologies Conference, May 16-20, 2005.

2. Craig W. Ohlhorst, et al., "Thermal Conduc- tivity Database of Various Structural CarbonCarbon Composites," NASA TM 4787, November 1997.

3. Smith, Russell W.; Sikora, Joseph G.; and Lindell, Michael C.: Test and Analysis of a Hyper-X Carbon-Carbon Leading Edge Chine. NASA/TM -2005-213765, May 2005. 